\title{
Ideología, modelo de mundo y sabotaje en tres cuentos de Álvaro Bisama*
}

\author{
Felipe A. Ríos Baeza
}

\begin{abstract}
Resumen
Este ensayo recurre de modo explícito a la teoría de los modelos de mundo y de ideología propuesta por Manuel Asensi Pérez en su libro Crítica y sabotaje (2011), la cual refiere que algunos discursos privilegiados, como la literatura, son capaces de deformar la percepción de los sujetos e imponer determinadas consignas sobre la realidad. Tomando en cuenta esta arista de la teoría de Asensi, se analiza la propuesta del escritor chileno Álvaro Bisama en tres de sus relatos más significativos, para demostrar que dicho autor recurre a una estrategia narrativa singular: por una parte, muestra cómo los protagonistas de sus relatos han deformado su visión del entorno; pero, por otra, cómo sus narradores impiden que esas visiones logren imponerse en el lector real de los cuentos.
\end{abstract}

Palabras clave: Modelo de mundo, ideología, sabotaje, Álvaro Bisama, narrativa chilena.

\section{Ideology, models of the world and sabotage in three short stories of Álvaro Bisama}

\begin{abstract}
This essay talks in an explicit way about the theory of the models of the world and the ideology proposed by Manuel Asensi Pérez in his book Critic and Sabotage (2011), in which he mentions that some privileged forms of speech, like literature, are capable of deforming the preception of the subjects and imposing specific tasks upon reality. Using this theory proposed by Asensi, the work of the Chilean writer Álvaro Bisama is analyzed through three of his most important stories, in order to demonstrate an only narrative strategy: on one hand, how the main characters of his stories have deformed the vision of their environments; and on the other hand, how the narrators stop these visions from being imposed into the actual reader of these stories.
\end{abstract}

Keywords: Model of world, ideology, sabotage, Álvaro Bisama, chilean narrative.

Este ensayo se inscribe en el Proyecto General “Análisis literario y estudios culturales en la narrativa hispanoamericana de los siglos XX y XXI”, investigación inscrita en el Consejo Nacional de Ciencia y tecnología (CONACyT), México.

Chileno. Escritor y Doctor en Teoría de la Literatura y Literatura Comparada por la Universidad Autónoma de Barcelona, España. Es autor de varios libros, entre ellos, El desvarío ilustrado. Ensayos de narrativa hispanoamericana contemporánea (2014) y Roberto Bolaño. Una narrativa en el margen (2013). Actualmente, es profesor-investigador del departamento de Investigaciones y Estudios Superiores, en el campus Querétaro de la Universidad Anáhuac, México, y es parte del Sistema Nacional de Investigadores del CONACyT, en el nivel I. feliperios.ffyl@gmail.com 
Faltan páginas aún para subrayar lo que El ingenioso hidalgo Don Quijote de la Mancha supone para el entendimiento del fenómeno literario. A partir de la novela de Miguel de Cervantes, la literatura explicita y vivifica su dimensión ficcional, en contraposición a su dimensión mimética; es decir, accede a la posibilidad de considerarse un mundo no sólo posible, sino autónomo. Sabiéndose autoconsciente de esa operación, el texto es capaz de insertarse en una tradición -la de las novelas populares y de caballería-, con el propósito de desapegarse de ella y torcerla, haciendo evidente el modo en que ese tipo de textos intenta imponer un modelo de mundo particular a sus lectores de época.

Ese desapego, esa distancia que establece con su referente -ya no un mundo empírico, el de las gestas históricas, sino el mundo replicado en la ficción por el Amadís de Gaula y el Orlando furioso- es lo que el teórico Manuel Asensi Pérez, en su libro Crítica y sabotaje (Barcelona, Anthropos, 2011), reconoce como condición sine qua non de El Quijote y, por inducción, de toda la literatura:

¿Y si, a fin de cuentas, El ingenioso hidalgo Don Quijote fuera de verdad una vituperación de los libros de caballería y, por extensión, de cierta literatura? [...]. Cervantes está arremetiendo contra el poder seductor de cierta "poesía», pues tiene efectos semejantes a la droga, crea dependencia y provoca una percepción alterada de la realidad. (Asensi 7, 9)

En Crítica y sabotaje, Asensi transita hábilmente por esos senderos y afirma que la literatura, desde su naturaleza y constitución, representa por excelencia uno de los mayores discursos deformantes de la realidad. Debido al carácter flexible de la misma, y a la capacidad de atraer sistemas colindantes (la política, la filosofía, la ideología) resulta el más indicado para absorber y proyectar su material performativo desde y hacia otros discursos: "La literatura es una lámpara deformante que convive o entra en conflicto con otro tipo de lámparas deformantes" (9). Por tanto, en la teoría del sabotaje dos asuntos son inmediatamente fundamentales: la manera en la cual la literatura organiza el mundo, y el modo en que la crítica literaria, luego del aporte indiscutible del postestructuralismo y los estudios culturales, apuntalan y disienten esa organización.

En este trabajo, y a la luz de la teoría desarrollada por Asensi, se persigue desentrañar, en la línea cervantina antes comentada, el sabotaje literario ejercido por el escritor chileno Álvaro Bisama (Valparaíso, 1975) en tres de sus textos más relevantes. El autor, dueño de una breve pero 
significativa obra -seis novelas cortas, un volumen de cuentos y cinco libros de crónicas ${ }^{1}$ - ha sido capaz de disponer en sus escritos una serie de materiales típicos del relato fantástico y de terror, pero, creemos, con otros propósitos que los subrayados por estudiosos anteriores.

En la crítica chilena reciente, la obra de Bisama ha sido examinada bajo diversos prismas para advertir algo que salta a la vista: en sus relatos late vivamente un conglomerado de manifestaciones alternativas a la cultura oficial, como el cine de terror, la ciencia ficción, el cómic, el rock pesado y las referencias apócrifas. Macarena Areco (2011), por ejemplo, afirma que su obra

[s]e caracteriza por la mezcla de subgéneros narrativos, especialmente populares; por la multiplicidad y la fragmentación en ámbitos como la estructura, el tiempo, el espacio, las voces y las tramas; por la desterritorialización que puede ser entendida como diseminación geográfica que supera el ámbito hispanoamericano, pero también como el cuestionamiento de los límites entre literatura y ficción, seres y objetos y entre géneros narrativos; y por la transtextualidad, según las cinco formas distinguidas por Gérard Genette. (182)

Por su parte, Ignacio Álvarez (2012) identifica la exposición de “subgéneros" en Bisama para catalogarlo como "narrador epicúreo", en contraposición a otros narradores, "escépticos" y "estoicos" de la literatura chilena de los últimos veinte años. Álvarez entiende que la referencia de Bisama a las películas de clase $\mathrm{B}^{2}$, el terror y los delirios fantásticos a lo Tolkien se debe a que,

[e]n su relación con el mundo [,] el narrador epicúreo se embarca en una empresa maníaca y creativa que es al mismo tiempo

La producción de Bisama comprende las novelas Caja negra (Bruguera, 2006), Música marciana (Emecé, 2008), Estrellas muertas (Alfaguara, 2010), Ruido (Alfaguara, 2012), Taxidermia (Alquimia, 2014), El brujo (Alfaguara, 2016) y próximamente Laguna (Alfaguara, 2018); el volumen de cuentos Los muertos (Ediciones B, 2013); y los libros de crónica y crítica literaria Zona cero (Edición del Gobierno Regional de Valparaíso, 2003), Postales urbanas (El Mercurio/Aguilar, 2006), Cien libros chilenos (Ediciones B, 2008), Televisión. Una antología en doce pulgadas (Lectura ediciones, 2015) y Deslizamientos. Crónicas y Ensayos (Ediciones Diego Portales, 2016). Además, ha participado en varias antologías de relatos, como Chil3: Relación del Reyno 1495-2210 (Ediciones B, 2010), Machetazos. Todos mueren (Ediciones B, 2013), We rock. Ocho historias rápidas y pesadas (Ediciones B, 2014), Todo es cancha. Antología de cuentos de fútbol (Alfaguara, 2014) y Por la razón o la fuerza: nuestra historia con Star Wars(Planeta, 2015).

2 Me refiero a las películas que tienen esa denominación desde los años treinta en Estados Unidos, que no solamente contaban con menos presupuesto, sino con tramas menos censurables que las de clase A y, por lo tanto, más inclinadas hacia la violencia y la extravagancia. 
gozosa y total: la proliferación del mundo y de los mundos. El empeño es total porque, tras aceptar su ordenamiento tal como puede percibirlo, el mundo ya no le ofrece secretos, se abre por completo al poder de su palabra; es también gozoso porque, libre de las amenazas del escéptico y las decepciones del estoico, el texto epicúreo articula un mundo cuya economía es el derroche, la infinita multiplicación de los objetos particulares. (22)

No obstante, creemos que los textos de Bisama se proponen algo más que el juego intertextual y la saturación de un mundo que, perceptiblemente, es opaco para su mera mímesis literaria. La hipótesis que guía este trabajo, y que se distancia de lo que otros críticos han comentado en torno al corpus literario de Bisama, es que la incursión en estos "géneros bastardos" ${ }^{3}$, al decir de Fabián Casas (2016), se lleva a cabo como una crítica ideológica a la usanza; es decir, para interrumpir precisamente sus efectos, para volver paródicos o "sabotear" con juegos metaliterarios los género mismos, hasta romper la expectativa de cualquier lector de estos tipos de manifestaciones. De esta manera, Bisama no sólo logra poner en entredicho el modelo de mundo de los personajes que interactúan en sus relatos, sino distanciarse del fanfiction, alertando sobre su fuerza performativa y, sobre todo, incitativa.

\section{Las nociones de modelo de mundo e ideología en la teoría de Manuel Asensi}

Una de las cuestiones más importantes que Asensi pone de relieve en la teoría que analizamos es que todo texto, debido a la encarnación semiótica que comporta, asume una posición y, por tanto, puede leerse ideológicamente. En la primera parte de su libro, titulado "Fundamentos para una crítica como sabotaje", el teórico es enfático al señalar que su propuesta alinea con una crítica "como desacuerdo y disidencia" (10) que postula un modo de leer textos y por tanto, el mundo. Para él, en los sistemas artísticos:

[...] no se trata de comunicar, sino de imponer una consigna y de lograr que los individuos participen de ella mediante sus acciones y sus discursos. El cine, la televisión, las páginas web, los

\footnotetext{
En su más reciente libro de ensayos, La supremacía Tolstoi y otros ensayos al tuntún, Casas afirma: “Los géneros bastardos como la ciencia ficción y la crítica de rock están produciendo verdaderas gemas al trabajar como soldadores de la alta cultura y la cultura de masas. A pesar de la resistencia conservadora, lo mejor surge en los campos de prueba de este mestizaje" (152).
} 
periódicos, las revistas, la radio, la ópera, las diferentes formas de publicidad, las exposiciones de los museos y de las diferentes instituciones, los libros de textos escolares y los discursos de los maestros y docentes en general, los ensayos, el teatro, la música y, por supuesto, lo que llamamos "literatura" y "arte" (novelas, libros de poemas, esculturas, pinturas, cartografías) son medios a través de los cuales se cumple la acción modeladora de los aparatos ideológicos heterogéneos y plurales del Estados, o del Imperio. (15)

En consecuencia, y tras la herencia consabida del postestructuralismo en su teoría, Asensi no piensa los textos literarios como simples artificios, objetos contemplativos o mero resultado del "uso especial del lenguaje": los textos literarios poseen, como la ideología, una estructura apelativa (interpelan a los sujetos) e incitativa (provocan acciones y/o maneras particulares de ver los fenómenos). Así también lo explicita:

El arte es una ficción, esto es, una deformación-modelización de la realidad fenoménica (una ideología), que produce efectos de realidad. Al hablar de 'efectos de realidad' quiero decir que el espectador o lector adquiere una percepción del mundo que en muchos casos le conducirá a actuar de un modo determinado en el mundo empírico. Y es claro que la actuación queda automáticamente ligada a la dimensión ética y política. (49)

Esto se debe, según Asensi, a que las obras de arte trabajan con lo que luego, en sus fundamentos, llamará "silogismo afectivo" o "afepto". La operación estriba en lo siguiente: como el discurso, el concepto y/o ejemplo de mundo que ellas exhiben ha logrado empatía con el sujeto, esa dimensión afectiva se transforma en dimensión efectiva:

[S]i atendemos a la manera como funciona un texto artístico, advertiremos que se corresponde con lo que podemos denominar "silogismo afectivo" [...]. [L] as rimas, la estructura sintáctica, la tropología, las connotaciones, constituyen la base afectiva del silogismo. No estoy argumentando nada parecido a que en un texto artístico tengamos dos dimensiones separadas: el silogismo como estructura profunda y la forma afectiva como estructura superficial, porque uno y otro plano son inseparables y constituyen una de las características más acusadas de la literatura y el arte en general. En realidad, la expresión 
"silogismo afectivo" describe una unidad funcional de la que depende, eso sí, la efectividad de su modelización. (32)

Por tanto, esos tres niveles (el ficticio-performativo, el modelizador y el ideológico/político), examinados antes en compartimentos distintos por la crítica literaria, el análisis ideológico y la sociología, respectivamente, quedarán estrechamente imbricados a partir del planteamiento de Asensi; articulación reflexiva que tendrá alcances mayores al mero entramado lingüístico de los textos y a la revelación de su significado en un sistema semiótico y/o sociocultural particular. Es justo decir, por ende, que entender la crítica como sabotaje no sólo pretende lograr un efectivo desenmascaramiento de las operaciones textuales que hacen posible esa performatividad/modelización/acción política, sino también, una operación de lectura subalterna:

La "crítica», en la acepción que la empleo aquí, es el ejercicio de un sabotaje de aquellas máquinas textuales lineales o no lineales (literarias, filosóficas, políticas, éticas, fílmicas, arquitectónicas, discursivas en general) que presentan una composición silogística entimémica como algo natural, transparente o mimética. $\mathrm{O}$ bien, la práctica de una cartografía de aquellos textos que funcionan como un sabotaje de determinado modelo de mundo. Esta distinción es importante porque subraya que la crítica como sabotaje presupone que existen dos clases generales de textos: los textos téticos cuya estrategia fundamental es la de ocultar su carácter entimemático o sus fisuras, y los textos atéticos que en su disposición dan a ver su composición silogística y ponen en crisis la posibilidad de esta composición. (53)

Así como saber distinguir los textos téticos -que presentan una composición silogística entimémica, requieren de un sabotaje por parte del lector-y los atéticos -necesarios para describir la acción misma del sabotaje-, es importante no pasar por alto cuestiones que serán cruciales para el análisis particular que se pretende: el de la narrativa de Álvaro Bisama. En primer lugar, hay que atender que la significación del texto literario no se encuentra sólo en su interior, sino que, al ser un entramado que se ha constituido refractando otras textualidades (por transposición, en el concepto más acabado de Julia Kristeva ${ }^{4}$ ), su lectura perseguirá asociar

4 "El término de intertextualidad designa esa transposición de uno (o de varios) sistema(s) de signos a otro; pero, puesto que ese término ha sido entendido a menudo en el sentido banal de 'crítica de las 
un conglomerado de sistemas posibles, relacionales, del modo rizomático que Gilles Deleuze y Félix Guattari postularon en Mil mesetas ${ }^{5}$. ¿ $Q$ Quién ha dicho que el sentido se reduce al universo lingüístico?” (34), se pregunta Manuel Asensi con acierto, ya que el sentido de una obra excede su mero mensaje o soporte de emisión. Se advierte, por tanto, que a la hora de la lectura, se tiene un signo que intenta imponer su ideología, y que se verá comparado con los distintos modelos de mundo en los que va recibiéndose.

De esto se desprende una segunda cuestión primordial, a contracorriente de ciertos enfoques hermenéuticos o semióticos tradicionales, y es que el sujeto no tiene una libertad amplia para "usar" el texto; es decir, la interpretación no depende, para el sabotaje, únicamente de su competencia, pues esto le quitaría la dimensión seductora e impositiva al texto y al lenguaje mismo: "Mantener esta tesis supone despreciar el poder de seducción de la obra de arte y del texto en general", determina el autor,

supone que el sujeto es inmune e impermeable a las influencias de los textos que llegan hasta él por diversos medios. Supone que un sujeto tiene la liberad de hacer lo que quiera con un texto, y el lenguaje no da lugar a esa independencia, tal como desde Lacan a Paul de Man ha quedado suficientemente demostrado. (42)

De este modo, habrá que convenir, contundentemente, que el texto literario implica algo más que un discurso estético o mimético cuando presenta (y defiende) posiciones téticas que generan ciertos tipos de comportamientos (asunto que se verá con toda claridad a los personajes dispuestos por Álvaro Bisama en los relatos escogidos).

Esta es la dimensión del texto literario que más nos interesa: su entendimiento como texto ideológico. Es sabido, desde Valentin Volloshinov, que la ideología se encarna en el lenguaje, lo que permite abrir un análisis material, concreto, de la literatura ${ }^{6}$. Pero ¿cómo hacerlo?

fuentes' de un texto, preferimos el de transposición, que tiene la ventaja de precisar que el paso de un sistema significante a otro exige una nueva articulación de lo tético -de la posicionalidad enunciativa y denotativa" (Kristeva en Navarro vii).

“[C]ualquier punto del rizoma puede ser conectado con cualquier otro, y debe serlo. Eso no sucede en el árbol ni en la raíz, que siempre fijan un punto, un orden [...]. En un rizoma, por el contrario, cada rasgo no remite necesariamente a un rasgo lingüístico: eslabones semióticos de cualquier naturaleza se conectan en él con formas de codificación muy diversas, esalbones biológicos, políticos, econónicos, etc..., poniendo en juego no sólo regímenes de signos distintos, sino también estatutos de estados de cosas" (Deleuze y Guattari 13).

${ }_{6} \quad$ "Un producto ideológico no sólo constituye una parte de la realidad (natural o social) como cualquier cuerpo físico, cualquier instrumento de producción o producto para consumo, sino que 
Si Louis Althusser afirmaba que lo más significativo del marxismo era que había adoptado un punto de vista de clase, una de las aristas finales y más importantes del sabotaje de Asensi es haber adoptado la posición del subalterno para observar los discursos. De este modo, el sabotaje mira desde ese lugar inferior donde se distinguen aquellas "situaciones invivibles y/o precarias" a las que los discursos nos han obligado como lectores o meros gestores de la circulación de cosmovisiones opresoras. En este sentido, explicitar, pues, el punto de vista del subalterno significa:

asumir la premisa según la que la mirada más privilegiada para alcanzar el conocimiento no es la que se sitúa en un afuera o en una posición superior, sino aquella que se ubica en los lugares más inferiores [...]; adoptar la posición del subalterno significa colocarse siempre y de forma constante en una posición crítica, en la negatividad. (Asensi 72-83)

Asumiendo que la operación saboteadora sólo es posible observando de ese modo, vale preguntarse, como alcance final, en qué punto textual concreto puede hacerse esa observación. Convenimos que, a pesar del distanciamiento saludable que Asensi toma con Derrida en el apartado “Deconstrucción y crítica y sabotaje" (58-64), su estrategia de lectura recordemos: la evidencia y el boicot de los silogismos entimémicos que sostienen un discurso apelativo-performativo- se volvería inoperativa si no se situara en ese "marco", "margen" o parergon enseñado por Derrida, que el mismo Asensi ya describiera en uno de sus textos más contundentes ${ }^{7}$ con el claro propósito de demostrar que, cierto límite que permitía distinguir esa interioridad de un discurso con la exterioridad de otros, iba paulatinamente disipándose. "La crítica como sabotaje sitúa en el centro de su análisis el texto concreto objeto de estudio y desde él irradia un sistema de relaciones cuyo fin último sería la interrelación entre diferentes discursos [...] con el fin de hacer notar los conflictos y/o alianzas que se establecen entre ellos" (Asensi 71).

En ese sentido, la teoría de Manuel Asensi tiene un positivo efecto colateral: se erige, también, como metacrítica. La consecuencia de ello

también, en contraste con estos otros fenómenos, refleja y refracta otra realidad exterior a él, todo lo ideológico posee significado: representa, figura o simboliza algo que está fuera de él. En otras palabras, es un signo. Sin signos no hay ideología. Un cuerpo físico es igual a sí mismo por así decir; no significa nada sino que coincida totalmente con su particular naturaleza dada. En este caso no hay problema de ideología" (La cursiva es mía; Volloshinov 32).

7 Vid. “Crítica límite/ El límite de la crítica”. 
tiene un doble sentido: por un lado, el sabotaje se separa de los modos habituales de crítica al ser un sistema mayormente complejo; de otra forma, no podría entregar esa dimensión política que resignifica esos conceptos que el poder mantiene neutralizados a su favor. Una de las resignificaciones más importantes que lleva a cabo opera sobre la noción misma de crítica: se trata no sólo de una herramienta para el análisis momentáneo de textos, sino -y como consecuencia de la apropiación del punto de vista ecléctico y desarticulador de la subalternidad- de una actitud coyuntural que evidencia que cuestionar, interpelar, poner en problemas un texto que aparenta dar una explicación o visión transparente del mundo es una forma actualizada de convertirse en "máquina de guerra".

Y por otro lado, si bien la crítica como sabotaje hereda de Deleuze, Spivak, De Man, Derrida, Adorno y otros la forma de mostrar elementos desatendidos por la crítica anterior, aquellas estrategias de lectura no habían sido capaces de mostrarse a sí mismas en su técnica, en sus códigos. Esa toma de conciencia es lo que Asensi llama el "sabertaje":

No sería excesivamente descabellado que, en consecuencia, la palabra "sabotaje" se convirtiera aquí en un "sabertaje" en donde lo que se sitúa precisamente como objeto y sujeto del sabotaje es precisamente el "saber», absoluto o relativo. De máxima importancia resulta en este punto reconocer que la crítica que estoy tratando de caracterizar aquí afecta tanto a las maquinarias textuales como a la actividad del crítico. (87)

Ese "sabertaje”, al hacerse explícito, logra en su operación de lectura que sus objetos de análisis también eleven a la superficie su manufactura, sus costuras textuales pero, ante todo, sus intenciones ideológicas.

\section{Raíces del poder del freak power: la estrategia narrativa de Álvaro Bisama}

Hasta su debut literario en 2006, Álvaro Bisama era un desconocido profesor de castellano de provincia, que había conseguido destacar por sus enérgicas crónicas en suplementos culturales de Santiago, en especial la “Zona de Contacto" y la "Revista de Libros", del periódico El Mercurio. En este último se encumbró con una columna, "El Comelibros”, donde comentaba desde la narrativa de Bolaño, Borges, Faulkner, Nabokov, las décimas de Violeta Parra y las obras de teatro de Jorge Díaz, hasta la literatura de Sturgeon, Philip Dick, Hugo Correa, Miguel Serrano y otras fantasías deli- 
rantes, como aquellas que aseguraban que, antes del golpe militar, Augusto Pinochet escribió cuentos y supo reunirlos en volúmenes de alta calidad. Todo esto aderezado con comentarios a películas de cine bizarro ${ }^{8}$ y discos, que iban desde el punk nacional al black metal más tenebroso. Con la publicación de Caja negra (Bruguera, 2006) -una reunión de relatos integrados $^{9}$ sobre eventos paranormales, cantantes glam, dibujantes de cómic y un diccionario apócrifo del cine de terror chileno-, Bisama inauguró, junto con Jorge Baradit, Francisco Ortega y otros, el movimiento freak power, humorada que provocó que la crítica, acostumbrada a los códigos de una novela chilena sobre la memoria dictatorial y el realismo, tuviera que repensar sus modos de lectura. La ciencia ficción, el humor negro, las referencias a la cultura alternativa, el terror y el relato fantástico se daban cita en una prosa rápida, fragmentaria, ágil, que se cuidaba, eso sí, de adherirse plenamente a las reglas operativas de un género en específico. Es decir, si bien en Caja negra (como en Música marciana, su segunda novela, de 2008) Bisama hablaba de un Chile trastornado y apocalíptico, más que replicar los modos narrativos de Sturgeon, Poe, Matthew Stokoe, Palahniuk o Lovecraft, aprendía de ellos una forma de expresión, sabiendo distanciarse de dichos referentes mediante la parodia o la crítica, para no convertir su escritura en una mera trasferencia perlocutiva.

Este desapego a una ficción que, como lo detallaba Asensi, intentaba imponerse a partir de un modelo de mundo basado en un silogismo falso, es característico de la estrategia narrativa de Bisama, quien en algunos de sus textos estará pronto a hacer cortocircuito, en momentos específicos de la trama, con el fin de que el lector sepa que la construcción de la ficción está mediada por la ideología del protagonista, o narrador, y que,

\footnotetext{
8 Si bien el término "bizarro" actualmente se considera un faux ami (es decir, un préstamo de otro idioma donde el neologismo no logra abarcar la exactitud semiótica deseada), conviene aclarar que en la década de 1990 lo «bizarro» servía para referir aquel cine de clase B, o cine de terror y violencia extrema. Diego Curubeto, uno de los máximos estudiosos latinoamericanos de este tipo de cine, lo aclara así: "Los aficionados a las películas de terror, sexo y violencia gratuita tienen una buena idea de qué es el cine bizarro. Pero como en el idioma castellano la palabra bizarro tiene un sentido distinto del que se le da en este libro, vale una aclaración. Los diccionarios suelen explicar que bizarro significa "valiente, espléndido, generoso". Nada que ver con el bizarre francés, que también fue tomado por el idioma inglés y que significa "extraño". La palabra viene del árabe y del vasco, y por algún motivo, desde hace ya más de un siglo se utiliza por la gente de habla hispana en su acepción teóricamente errónea" (Curubeto 15). $9 \quad$ Se utiliza aquí la definición de relatos integrados tal como la entiende José Sánchez Carbó en su libro teórico La unidad y la diversidad. Teoría e historia de las colecciones de relatos integrados (2012): "La colección de relatos integrados resulta así una modelización literaria caracterizada porque un autor reúne y organiza en un libro una serie de textos autosuficientes que, relacionados hipotáctica o paratácticamente, configuran, con la colaboración del lector, un todo coherente y permiten un orden de lectura sucesivo o salteado" (46).
} 
como lectores, sólo queda contemplar ese mundo, sin posibilidad de acceder a la esfera incitativa.

Esta intencionalidad aparece explícita en algunos de sus textos periféricos. Por ejemplo, a mediados de 2013, Bisama inició un profuso intercambio ciberepistolar con el novelista mexicano Tryno Maldonado. En uno de esos correos, Bisama realizaba la siguiente afirmación:

[E]l satanismo la lleva. Acá [en Chile] es cosa de todos los días. Hasta las sectas new age hacen sacrificios: hace un par de meses se descubrió que unos idiotas quemaron un bebé de dos días porque el líder les dijo que era el Anticristo. El tipo terminó ahorcándose en el Cuzco y antes, castigaba a los miembros de su secta pegándoles cincuenta veces con un palo, mientras ellos guardaban silencio. Por mi lado, sirve para la escritura: yo mismo terminé una novela medio black metal que ahora está en reposo, fermentando. (Intercambio párr. 12)

En esta cita hay una cuestión importante a tener en cuenta para este análisis. Primero, con el giro idiomático "la lleva”, Bisama hacía alusión, en un chilenismo común, a que el satanismo deslumbraba, producía una suerte de hechizo, aunque, como se comprobará rápidamente, sólo en su dimensión especulativa. "Por mi lado, sirve para la literatura" es una frase que, de manera evidente, marca para el autor la división entre ciertos sucesos de un contexto convulsionado con los que no parece comulgar y que, sin embargo, servirán como "fermento" para su literatura. Esta división sirve para comprender cómo la literatura de Bisama -truculenta, violenta, mórbida- tiene como procedimiento el desapego de los referentes, para elaborar, luego, una ficción autosuficiente.

La novela Black metal a la que hace alusión acabó llamándose Póser, y es, a nuestro entender, uno de los tres textos en los que se trabaja con mayor rigurosidad este desapego, o sabotaje, no sólo de la mímesis literaria, sino incluso del desvío de una tradición, a saber, el relato fantástico y de terror.

Es por este motivo que, al alero de la teoría del sabotaje de Asensi, pretendemos realizar un análisis de esos tres textos que nos parecen más arriesgados de la producción de Bisama: el relato "La dieta del orco" (aparecido en su libro de cuentos Los muertos, de 2014); el cuento "Grindcore sudoku" (incluido en la compilación de la Radio Futura, We rock. Ocho historias rápidas y pesadas, de 2014); para acabar con la novela 
corta Póser (del libro colectivo Machetazos. Todos mueren, de 2013), el texto más complejo, pero, al tiempo, donde mayormente pueden verse desplegadas las habilidades para mantener ese distanciamiento entre ficción (convencida de su efectividad e imposición de visión de mundo) y metaficción (como crítica con esa imposición). Lorena Amaro (2014) ya había advertido que, por ejemplo, los relatos de Los muertos "tensionan las posibilidades del cuento con pasajes metanarrativos y autoficcionales, entre otros procedimientos que le dan nuevo espesor al formato" (Amaro párr. 13). No obstante, se verá cómo ese espesor logrado, ya sea por la proliferación de referencias a la cultura alternativa, o bien por estos procedimientos de autoficción, no impide ver el movimiento de fuerte crítica ideológica que en él se cobija.

\section{3. "La dieta del orco": un sujeto hecho de alta fantasía}

Así se autocalifica el narrador de este relato: como un sujeto hecho de "alta fantasía"; pero en realidad se trata de un hombre de mediana edad, que vive con su madre debido a que su pareja lo ha dejado, y que comienza a sentir los estragos corporales, mas no intelectuales, del paso del tiempo. Todo ello está contado de manera abrupta, en un solo y largo párrafo, sin puntos, en el que, como se verá, la naturaleza propia del relato fantástico (desde las sagas épicas hasta el fanfiction) intenta ser desmantelada a través de dos estrategias: el lenguaje coloquial y los detalles de la vida cotidiana del propio protagonista.

En efecto, su pareja lo ha dejado: "La mina me dejó, hueón; no cachó que yo estaba hecho de alta fantasía y se fue cagando [...]" (Bisama, Los muertos 53). Las estrategias discursivas saboteadoras empleadas en este inicio se vincularán, por semejanza, a las comentadas por Asensi a propósito de $E l$ Quijote, donde la burla y la crítica a cierto tipo de género (las novelas de caballería) se produce no sólo en el plano del contenido, sino también en el plano de la expresión ${ }^{10}$ con el fin de introducir el abaratamiento (o disforia, en términos líricos ${ }^{11}$ ) propio de

10 A los inicios elocuentes y vivaces de Los cuatro libros del virtuoso caballero Amadís de Gaula o de El libro del Caballero Zifar se le contrapone: "En un lugar de la mancha, de cuyo nombre no quiero acordarme" (La cursiva es mía; Cervantes 27).

11 Empleamos, aquí, los términos euforia y disforia del mismo modo que en poesía se trabaja el tono de la enunciación. Como explica Juventino Caminero (1998): "Los grandes poetas obedecen en su práctica como creadores de realidades subjetivas al control objetivo de los universales del sentimiento, de acuerdo con un movimiento pendular, que se materializa en dos direcciones contrapuestas, las cuales 
todo discurso paródico ${ }^{12}$-. En "La dieta del orco", el tono propio de los relatos fantásticos -"En el principio estaba Eru, el Único, que en Arda es llamado Ilúvatar; y primero hizo a los Ainur, los Sagrados, que eran vástagos de su pensamiento, y estuvieron con él antes que se hiciera alguna otra cosa" (Tolkien 15), por ejemplo- ya aparece boicoteado, intervenido, con un dato personal enunciado, además, en el más cerrado argot chileno ("La mina me dejó, hueón"; "no cachó"; "se fue cagando"). El narrador ha sido abandonado y ese abandono es la pérdida del punto de referencia, pues el volver a vivir con su madre y deambular en centros de reunión de quienes gustan del género fantástico (el Portal Lyon, por ejemplo, centro comercial ubicado en Santiago de Chile, famoso por sus tiendas de animación japonesa, juegos de rol, cine bizarro y videojuegos) se convertirán en los caminos laterales a transitar después de esa separación.

Durante todo el cuento, el narrador hace referencia a un mundo en el que pretende trascender, el de la literatura de fantasía, que conoce plenamente y que, incluso, intenta reproducir, y otro que le desagrada y que pretende, sin éxito, modificar a partir del primero, el de su cotidianidad. El uso del narrador autodiegético y el modo en que se imbrican ambos mundos son dos de los recursos a los que apela Bisama en aras de lograr un texto en el que casi cada renglón desactiva al anterior, provocando que, lo que podría haber nacido como relato fantástico, se anule ante la inminencia de un relato realista:

[...] me fui a la chucha, culiao, a la reverenda chucha, onda que salía en las mañanas y me paseaba por el Portal Lyon buscando a los pendejos para jugar a las cartas y los hueones me cachaban ahí, flaco y medio pelado y como que me tenían miedo, como que tenía pinta de pervertido pero nada, ni un rollo, si soy más bueno que la cresta, onda nunca me he ido a las manos en mi vida y eso se los decía a los pendejos, les decía que tenía mis cartas y que era fanático del profesor Tolkien y que

pueden ser denominadas euforia y disforia. Dentro de estos extremos se aloja una serie indeterminada de tonalidades" (275).

12 Se utiliza parodia al modo en que Gérard Genette entiende que tuvo origen el término: Ôda, es el canto; para: "a lo largo de», "al lado»; parôdein, de ahí parôdia, sería (?) el hecho de cantar de lado, cantar el falsete, o con otra voz, en contracanto -en contrapunto-, o incluso cantar en otro tono: deformar, pues, o transportar una melodía [...]. En un sentido todavía más amplio, la trasposición de un texto épico podría consistir en una modificación estilística que lo transportaría, por ejemplo, del registro noble que es el suyo, a un registro más coloquial, e incluso vulgar (Genette 20-21). 
la hueá del rollo de la literatura fantástica me rayaba en mala y los pendejos me escuchaban y me preguntaban hueás y yo me pasaba el día así y cuando tenía hambre me metía al Burger King o al McDonald's y me comía una hueá barata y volvía a sentarme en el suelo y ellos me preguntaban por mi vida [...]. (Los muertos 53)

El fanatismo por J.R.R. Tolkien, que lleva al personaje a afirmar a sus jóvenes contertulios que "en realidad Chile tenía su propia Tierra Media en los bosques del sur" (54), es fuertemente contrastado y puesto en entredichos incluso en su posibilidad de erigirse como relato de género. En este párrafo específico, son los elementos patéticos los que provocan la interferencia. Empleamos aquí patetismo en su acepción retórica (pathos), como un exordio dispuesto a provocar rechazo y vergüenza ${ }^{13}$, asunto que es posible evidenciar tanto en la expresión (el comentado argot del personaje) como en el contenido (su aspecto físico y su forma de subsistencia: el alimentarse en locales de comida rápida, lo que desactiva también cualquier expectativa que pudiera haberse generado en el título: la "dieta" de este "orco", este monstruo no celta sino radicalmente chileno, es finalmente la ofrecida por el capitalismo a nivel global).

Con ese primer nivel desmantelado (lo que come el orco), viene una segunda estrategia saboteadora: desactivar no sólo a quien narra sino también lo que se está narrando. Y en este plano, serán sus interlocutores quienes llevan a cabo esa operación:

[...] les hablaba del profesor Tolkien y de cómo cresta había aprendido a escribir en el alfabeto élfico, les hablaba de la dieta de los orcos y de los hobbits y ellos me decían que los hobbits eran todos maricones, que se gastaban parejo entre ellos, que los culiaos eran entero huecos y que el profesor Tolkien también, que no le creían nada y que la película era una mierda pero yo me defendía porque les contaba que en realidad Chile tenía su propia Tierra Media en los bosques del sur [...]. (La cursiva es mía; 53-54.)

Bisama logra, en este párrafo inicial, encuadrar su estrategia saboteadora. Por un lado, el modelo de mundo ficcional del narrador es el de un lector -no ya de novela de caballerías, aunque de todas

13 Vid. Aristóteles. 
maneras desea "desfacer tuertos" - que deforma la realidad a partir de las estructuras narrativas de Tolkien y “de esa minita que escribía Las nieblas de Avalon y ese guatón culiao del Juego de tronos y Robin Hobb y el seco, sequísimo, de Steve Ericsson que me encantaba porque todos ellos me rayaban y tenía sus libros en el estante de la pieza [...]" (57). Pero por otro, el modelo de mundo metaficcional, que aparece en los elementos, párrafos y líneas que hemos dado a llamar disfóricas, aterriza cualquier revuelo hacia las costas de lo fantástico no del personaje (quien prueba llevar la "alta fantasía" al plano performativo, a través de sus pláticas con los jóvenes y, como se verá posteriormente, de sus propios intentos de escritura de fanfiction), sino del lector de este cuento. Lo que pretende Bisama, y que dicta la pauta para el resto de sus textos de este corte, es que no exista identificación entre lector y personaje. Aunque el personaje, como puede ser el caso de ciertos lectores, confíe en su empresa de proyectar el mundo ficcional en el mundo que habita -ya que confía en "las ciento catorce veces que había leído El Silmarillion mientras pensaba que ojalá termine esto pronto [...]" (57)-, las situaciones privadas y el modo en que están enunciadas discontinúan esta posibilidad.

Si la expectativa inicial por el relato, debido al título ("La dieta del orco"), se trunca una vez que se sabe que el personaje es un simple lector obsesionado con el género, que come sin mucho afán los menús más económicos de Burger King y McDonald's, este movimiento (de lo épico a lo cómico, diríamos) acaba de solidificarse cuando se conoce que no solamente lee, sino que escribe una saga fantástica, denominada El cálix de la serpiente:

[...] yo estaba escribiendo una novela, hueón, una novela inmensa de la que llevaba dos mil páginas, una saga de cinco libros, que era mi homenaje al profesor Tolkien pero también a los guerreros mapuches del siglo XVII, una novela que se llamaba El cálix de la serpiente y que trataba de un príncipe bastardo al que sus hermanos odiaban en un mundo de islas hechas con pura roca volcánica que los humanos sólo podían cruzar arriba de unas serpientes voladoras [...] mi novela se volvía oscura porque en el quinto tomo la guagua había crecido y volvía a vengarse de su padre y ya no tenía rostro porque no tenía cabeza [...]. (54)

[Y] yo escribía todo eso y llenaba todo de una prosa fantástica, hueón, una prosa épica que ya se la quisiera cualquier poeta 
culiao, donde alguien levantaba su flamígera espada hacia el cielo azafranado dibujando un arco de centellas que se abría paso sobre los broches dorados de una armadura forjada de soles, hueón, y escribía eso mientras pensaba cómo cerrar el arco narrativo, porque aquí había un arco narrativo, conchetumadre, el medio arco narrativo, culiao, porque yo había hecho la pega y me había leído tres libros gringos sobre cómo escribir novelas [...] me quedaban como cien páginas para terminar y no me decidía si el hijo de fuego azul mataba a su papá o el papá mataba al hijo o el hijo quemaba con su abrazo al fantasma agusanado porque era una decisión cabrona, hueón, una decisión compleja porque ahí se me iba a la cresta el arco narrativo, ahí se me iba la vida, me la jugaba todo el por todo en ese cierre [...]. (56-57)

Esta segunda característica, la del lector que proyecta su ideología -es decir, su modelo de mundo articulado a partir de la "lámpara deformante" del género fantástico- no sólo en sus interlocutores más jóvenes, sino en el papel, complejiza y sofistica aún más la estrategia de Bisama. Por supuesto que en la empresa de los cinco tomos de El cálix de la serpiente se le deshace (o "se le va a la cresta", en buen chileno) el arco narrativo y la vida: el protagonista está dejando testimonio de un río subterráneo, un discurso metatextual, que hemos dejado para el final de este apartado: la situación familiar que se desarrolla en la convivencia, casi nula, con su madre.

El personaje secundario de la madre, aunque de aparición esporádica, es determinante para este relato, comparable quizá, por sus características, al de la madre-cloaca de Martín, protagonista de Sobre héroes y tumbas de Ernesto Sábato. "[Y]o me quedé solo en la casa con mi vieja que hablaba puras hueás de que extrañaba a mi papá y me fui a la chucha [...]" (53), puede leerse en "La dieta del orco". Mientras el hijo escribe los cinco tomos de homenaje, la madre absorbe y proyecta su propia saga fantástica, y con final épico, a partir de la televisión:

[...] me iba para mi casa y ahí estaba mi vieja, viendo las noticias, pegada con Megavisión, asustada, cagada de miedo porque Chile se había llenado de delincuentes, porque en cualquier momento alguien se iba a saltar la muralla del patio y se iba a llevar la tele [...]. (53-54) 
[... mi madre gritaba de alegría en su pieza porque veía un programa de mierda en Megavisión donde los pacos entraban a la fuerza a la casa de unos narcos y ella se alegraba porque estaban barriendo a esa basura, estaban apresando a esos delincuentes que le daban droga a los niños de Chile, a los asesinos que traían ese flagelo que había enfermado el país, gritaba mientras yo escribía sobre el duelo final entre padre e hijo [...]. (56)

Si el hijo tiene modelado el mundo a partir de la literatura fantástica, la madre tiene un modelo de mundo impuesto por los medios masivos de comunicación, únicos estímulos para volcar el temor y el alivio de un entorno que le parece más amenazante de lo que realmente es. Y aquí el cuento ya no va de lo épico a lo cómico, sino de lo cómico a lo conmovedor: ambos habitantes de esa casa están buscando la protección de una amenaza porque, en su imaginario, quien deería protegerlos no está: el padre.

Finalmente, "La dieta del orco", en sus escasas seis páginas, no sólo denota la fantasía de dos personajes, el narrador y su madre, a partir de una carencia (la del padre), sino que, probablemente, esté volviendo explícito el metatexto de buena parte de la literatura de género fantástico: la apelación exagerada, descomunal, a la protección de una figura paterna, que en los textos de este corte se presentará bien como contrincante, bien como ausencia.

\section{4. "Grindcore sudoku": del grito al silencio}

En el mismo 2013, la Radio Futuro de Chile y ediciones B decidieron reunir a un grupo de escritores jóvenes, afectos a las manifestaciones más viscerales de la música, y publicar We rock. Ocho historias rápidas y pesadas. Para ese volumen, Álvaro Bisama aportó “Grindcore sudoku”, cuento que, a nuestro parecer, surge de la misma matriz creativa que "La dieta del orco", aunque para problematizarla aún más. En este caso, la modelización de mundo y la performatividad ideológica, descritas más arriba según los puntos de vista de Asensi, ya no se focalizarán exclusivamente en el devenir de un personaje, sino en lo que ocurrirá con dos grupos bien definidos. Por un lado, accederemos a las consecuencias (rápidamente interrumpidas), en la vida del narrador y los personajes secundarios, de la recurrencia a, así como de la incitación ideológica propuesta en un género musical, y, por el otro, a los efectos del mismo género en la vida 
del protagonista, (que va transformándose, modificando verdaderamente su conducta hasta el final, que se presenta como abierto y que adelantará otras narraciones del autor).

De esta manera, en "Grindcore sudoku" no asistimos al recurso de la narración autodiégetica para conocer los diversos sistemas presentes en el modelo de mundo o percepción alterada del protagonista -lo que Asensi bien reconoce, al alero de Kant y de Even-Zohar, como "un largo polisistema de deformaciones [...], una estética trascendental que lleva a percibir el espacio, el tiempo y el movimiento de un modo precodificado" (9-10)-, sino al testimonio secundario. Es otro, un testigo, quien va a focalizar y contar esta historia. Y la historia es la de un personaje curiosamente parecido al fanático de la literatura fantástica de "La dieta del orco": "Fue el vocalista de la única banda grindcore que alguna vez tuvo mi pueblo”, inicia el cuento. “Tenía cara de viejo y era pálido, con esa especie de palidez que simula un blanco sucio, como orina de enfermo" (We rock 21). El aspecto físico y su comportamiento, mediado por el género musical, volverá a fungir como anomalía para un entorno más bien opaco y aburrido, donde los demás personajes, al igual que los jóvenes del Portal Lyon en "La dieta del orco", representan simplemente una masa:

Apenas hablaba de corrido. Pero cuando subía al escenario se convertía en un animal. Se enrollaba el cable del micrófono en el brazo y se ponía a gritar sobre la necrofilia, los perros vagos y el acoso de la policía. La banda no era buena [...]. [P]or aquellos años, todos los fines de semana había conciertos en sedes vecinales, canchas de fútbol y bares que se caían a pedazos. Se hicieron famosos ahí. Consiguieron sus primeras pololas de inmediato. Antes de que cada uno de ellos tuviera veinte años, ya eran considerados estrellas por los tipos que se juntaban en la plaza del centro antes de irse a tomar a la línea del tren. Yo los vi por esa época. Una polola me llevó [...]. El público que los seguía tenía fama de violento. En uno de esos improvisados mosh pit con suelo de tierra habían acuchillado a un niño. La banda había grabado un par de casetes en el living de una casa. Esos casetes circulaban de mano en mano. Sonaban como la mierda [...]. Por un tiempo se dejó un mohicano y por otro empezó a usar unos lentes de señora que le había robado a su abuela. (21-22) 
Nuevamente, con la velocidad propia de su prosa, Bisama fisura, para el lector, el sistema que le otorga al protagonista su peculiar ideología. Se percibe una estrategia de distanciamiento y disforia ya conocida: el grindcore, una de las expresiones más agresivas del punk, cuyas letras siempre constestatarias pueden ir desde la denuncia a los aparatos represivos del Estado hasta descripciones grotescas del cuerpo humano y sus expulsiones, se presenta como la primera matriz ideológica capaz de afectar la visión de mundo del personaje (y de sus seguidores violentos); pero se muestra inmediatamente matizada, interrumpida por contrapuntos críticos, impidiendo sus intenciones de articularse como relato exclusivamente ficcional: "Sonaban como la mierda" (22); "empezó a usar unos lentes de señora que le había robado a su abuela”, etcétera.

Si detrás de su espeso nivel de fantasía, "La dieta del orco" narraba, en realidad, la historia de una mujer y un hijo que intentan saturar la ausencia del padre con la televisión y la fanfiction, "Grindcore sudoku" está contando otra historia debajo de aquella, que tiene al vocalista del grupo grindcore como estrella invitada. Es más, tensando el arco, diríamos que no cuenta una, sino dos historias subterráneas: la de una juventud que se vincula y recrea en circuitos alternativos (mas, de pronto, es absorbida irremediablemente por los códigos sociales del sistema) y la del propio narrador heterodiegético (y su complejo entendimiento del mundo más allá de las fronteras de ese pueblo en el que se desarrolla la trama).

El primer caso es explícito y hace pensar en lo comentado por Gilles Deleuze y Félix Guattari en torno al riesgo de "molarización” de las "líneas de fuga", en tanto "principio de ruptura asignificante"14. El narrador, personaje habitual de esos circuitos de punk, metal y trash, argumenta en un momento: "Duré en eso dos años, hasta que en la universidad me di cuenta de que tenía que ponerme a estudiar realmente" (la cursiva es mía; 23). La institución universitaria, por tanto, provoca un alejamiento del narrador tanto del pueblo como del entorno del grindcore,

\footnotetext{
14 “Todo rizoma comprende líneas de segmentaridad según las cuales está estratificado, territorializado, organizado, significado, atribuido, etc.; pero también líneas de desterritorialización según las cuales se escapa sin cesar. Hay ruptura en el rizoma cada vez que de las líneas segmentarias surge bruscamente una línea de fuga, que también forma parte del rizoma. Esas líneas remiten constantemente unas a otras. Por eso nunca debe presuponerse un dualismo o una dicotomía, ni siquiera bajo la forma rudimentaria de lo bueno y de lo malo. Se produce una ruptura, se traza una línea de fuga, pero siempre existe el riesgo de que reaparezcan en ella organizaciones que reestratifican el conjunto, formaciones que devuelven el poder a un significante, atribuciones que reconstituyen un sujeto: todo lo que se quiera, desde resurgimientos edípicos hasta concreciones fascistas. Los grupos y los individuos contienen microfascismos que siempre están dispuestos a cristalizar" (Deleuze y Guattari 15).
} 
transformándolo en alguien que parece alinearse con los patrones de comportamiento exigidos socialmente. La misma situación padecerá su antigua pareja: "Supe que mi antigua polola quedó embarazada de un trasher y se casó. Se mudó a Santiago" (23). Las tres situaciones (el embarazo, el consecuente matrimonio y el movimiento de la provincia a la capital chilena) serían, siguiendo a los autores de Mil mesetas, codificaciones propias del capitalismo. El derrotero de los personajes secundarios de este cuento es amargo: a pesar del brote enérgico de la música grindcore en su pueblo, en tanto polisistema capaz de otorgarles un desenvolvimiento alternativo al del resto de los habitantes, los personajes acabarán siendo absorbidos por aparatos ideológicos, institucionales, como la universidad y el matrimonio, que los hacen despegarse de la visión de sus años de adolescencia. El segundo caso, el del narrador heterodiegético, se deriva del primero, y lo comentado por él mismo al final de esta secuencia narrativa es elocuente: "Yo me fui del pueblo y luego volví para quedarme. Supe que nunca iba a poder salir de ahí" (23); "desde el patio miré los cerros que eran nuestro cerco" (25).

Por tanto, se evidencia en las narraciones de Bisama una suerte de conservadurismo social: a pesar de modelizar la visión de mundo con unos códigos, los del grindcore, se acaba siendo apelado y performativizado por los dispositivos archiconocidos del capitalismo. En este cuento, solo el vocalista parece ser el único capaz de advertir esas codificaciones e intenta romperlas. Al igual que el narrador, también ingresará a estudiar a la universidad y terminará como profesor de Historia en La Reina, una comuna de clase media de Santiago, pero la herencia escurridiza del grindcore le impedirá aceptar el mandato jerárquico institucional con convencimiento:

En un colegio de La Reina intentó armar un sindicato y lo echaron. En otro decidió no enseñar nada. Compraba esas revistas llenas de sudoku y se pasaba la semana llenándolas mientras los muchachos escuchaban radio, se besaban o simplemente dormían [...]. Empezó a invitar a los adolescentes del barrio a su casa y les mostraba sus viejos demos que guardaba en una caja de zapatos [...]. Uno de los muchachos de la cuadra le enseñó a hacer tatuajes. Tenía cierta habilidad en eso y se tatuó a sí mismo en la mano izquierda. (24)

Ese derrotero contempla, primero, ingresar en un sistema sin cumplir con sus códigos (ya no se trata de una forma de protesta con alaridos 
y letras subversivas, sino de la silenciosa disconformidad de resolver sudokus cuando debería impartir clases (o "consignas", al decir de Deleuze) y preocuparse por la educación de la juventud chilena; después, y tal como ocurría en "La dieta de orco", alimentarse del reconocimiento de los jóvenes, a quienes, con el reposo de los años, los modeliza con la misma matriz ideológica con la que él fue modelizado en su pueblo de provincia (el grindcore), y finalmente, dejarse influir por una nueva actividad de esos jóvenes: los tatuajes. Esto será significativo, porque, al final del cuento, el vocalista será capaz de reinventarse, como una nueva línea de fuga, y se abrirá la posibilidad de interrelación entre "Grindcore sudoku” y el texto que resulta el más arriesgado de Álvaro Bisama hasta el momento (la referida novela black metal, "Póser"), cuando se lee: “[E]1 vocalista avisó que de ahí en adelante solo tatuaría imágenes del diablo" (25).

\section{5. "Póser": un terror vaciado}

Esta novela corta (veloz, fragmentaria, alborotada: elementos propios de la estrategia narrativa del autor, finalmente), abre el volumen Machetazos. Todos mueren, compilación de cinco historias de terror que según Patricio Jara, su editor, es capaz de "recoger las señales del entorno y devolverlas convertidas en literatura" (9). Una de esas señales, precisamente, desactiva de entrada la posibilidad de que la causa que provoca terror en la novela de Bisama (la conversión del protagonista al satanismo) pueda asumirse plenamente como modelo de mundo convincente para el lector. En pocas palabras, serán las mismas señales del entorno (partiendo por el propio modismo del título, "póser") las que impidan la consolidación de la de Bisama como "novela ejemplar" del género.

El recurso para enunciar esta historia es el multiperspectivismo, debido a que lo que se narrará en el plano de la ficción tenderá a ser más problemático, más violento y por tanto más alejado de lo que Bisama desea transmitir en el nivel metaficcional más hondo. Como escenario aparece nuevamente la provincia chilena (en este caso Castro, en el Archipiélago de Chiloé), en tanto presencia amenazante de los códigos sociales de la capital. Son varios los personajes que construyen esta historia, la historia de la aparición repentina de un niño que, como recurso ominoso, incomoda y vuelve más agresivos a los personajes secundarios que están a su alrededor: "Empezamos a pelear menos", 
dice la madrastra del niño al comienzo, cuando el padre aparece con él en la casa, "pero éramos más violentos. Cuando crecía recuerdo que se quedaba de pie, en silencio, mirando cómo su padre trataba de matarme. Ese niño era mi hijo falso, el que nunca tendría" (Bisama 14).

Esta dislocación en el equilibrio de la historia, a raíz de la aparición espontánea de un niño de origen difuso en una comunidad, se verá complementada por lugares comunes propios de una historia que tendrá al satanismo como ideología: "Después supimos que al papá lo metieron en un sanatorio en Puerto Montt [...]. [La madre y el hijo] [a]ndaban con la Biblia para todos lados [...]. Después empezaron a esfumarse los animales del barrio" (14).

El niño secuestra a los animales del vecindario y a las pocas personas con las que convive les confiesa que escucha voces y habla con los muertos. El testimonio de uno de sus amigos expresa de este modo el desencadenamiento, diríamos inefable, de una historia de este tipo:

Un día me dijo que me iba a mostrar algo. Nos metimos a un bosque cerca de la población [...]. Hablaba de los brujos que habían vivido en la isla, de un ser al que le cosían los agujeros y le quebraba la cabeza, de una llave mágica. Yo no entendía nada y pensaba que era una película de terror que había arrendado en un video club de Castro [...]. En un momento llegamos a un claro. Había una carpa hecha con bolsas de basura y lona. Me dijo que era su casa secreta, que huía ahí para hablar con sus amigos. Le pregunté quiénes eran sus amigos. Dijo que no me podía decir pero que le pedían regalos. Entramos a la carpa y me mostró una mesa hecha de tablas rotas llena de cabezas de animales. (La cursiva es mía; 15)

El cine de terror y sus recurrencias (vibraciones malignas, actividad paranormal, leyendas, maldiciones, personajes introspectivos) aparecen, por tanto, como discursos modelizantes, casi como un patrón estéticoideológico que resulta fácilmente parodiable. No obstante, aunque se intente provocar ese distanciamiento paródico con el referente, resulta interesante cómo de todas maneras el protagonista modeliza a su interlocutor a través de esa matriz (la del cine de terror), provocando, como efecto performativo, el temor o repulsa: "Cuando llegué a la casa pensé en acusarlo, pero temí que me podía venir a matar por la noche, que me iba a cortar la cabeza" (15). 
Esto establecerá un patrón en cada personaje que otorga su testimonio, cargado con miedo o repugnancia hacia el protagonista. Por un lado, se explicita la supuesta certeza de los personajes de haberlo olvidado o sacado de sus vidas: "nunca le hablé más" (15); “dejó de ir a los cumpleaños" (23); "le dijimos que no se apareciera más, y si lo hacía, que se quedara mudo” (24); “¿Si lo echamos del departamento? Lo echamos. Sí” (27), etcétera. Pero, por otro, resulta evidente cómo su recuerdo genera una intranquilidad que perdura y que enturbia la visión del presente de esos testigos: "tuve pesadillas por semanas" (24); "el papá había desaparecido, iba y venía. Mejor ni tocar el tema" (16); "la mina tuvo que tomar un calmante. Fue una noche de mierda" (24).

Ahora bien, al igual que en "Grindcore sudoku”, en "Póser" la música será también uno de los discursos performativos más poderosos para el protagonista, al punto de provocar, en él, el convencimiento irrestricto de lo decretado en las letras de las canciones. “Tenía cualquier disco" (20), dice uno de los testigos, y las bandas que se citan como paradigmáticas son aquellas que transitan por las variantes más radicales del death, trash y black metal: "Deicide”, "Destruction", "Kreator", "Entombed”, "Darkthrone", etcétera ${ }^{15}$. Ésta es la "lámpara deformante" que provoca que, del sacrificio animal realizado por el protagonista durante su infancia, se pase, en la juventud, a la profanación de tumbas y a la revelación de aquello que le dictan las voces:

[L] a profesora jefe nos dijo que quería hablar con el curso porque había pasado una situación gravísima y quería que le dijéramos si sabíamos algo. Nos contó que alguien, de noche, se había metido al cementerio y había desenterrado el cadáver de nuestra compañera. (22)

El culiao se ponía raro cuando tomaba. Cuático. En mala. Hablaba de la Recta Provincia, de la Mayoría, de los brujos. Decía que éramos sus herederos, que éramos sus hijos [...]. Él hablaba de una cueva. En la cueva había un libro de magia

\footnotetext{
15 Una muestra al azar, como ejemplo: en la canción "Mephistopheles", aparecida en el disco homónimo de Deicide puede oírse: "Aggravated blasphmere, insurrected one to tell/ power through defile/ Mephisto is coming to calim me for hell/ Satan/ take me Mephistopheles" (Benton 1990); mientras que en "Son of Evil", del disco Endless Pain, de Kreator, se canta: "Born in the demonic room of hate/ torture is in his eyes like a glowing blade/ inhuman soul like an animal beast/ the blood of Jesus one thousend people fall the priest/ son of evil" (Fioretti, Petrozza, Reil, 1985).
} 
y una llave. La cueva quedaba en Quicaví, pero su ubicación exacta se ha perdido.

$[\ldots]$

[U]n día llegamos tarde de no sé dónde y él estaba desnudo en el living con una gallina descabezada en la mano [...]. Tenía la cara manchada con sangre, estaba todo iluminado con velas, se había cagado en el piso [...]. Las paredes y el suelo estaban pintados con sangre. Había hecho unas runas o algo. Había un pentagrama deforme en el piso. (27)

El recurso mimético del discurso oral opera aquí de forma distinta a como ocurre en "La dieta del orco". En este sentido, los testimonios -que, debido a su velocidad y soltura, parecen jirones de historiahacen evidente la intención de reproducir el discurso oral a partir de modismos ("culiao", "cuático", "en mala”) pero, en lugar de provocar disforia y distanciar al lector del evento, están cargados semánticamente de la reacción de un miedo genuino. Los testimonios pretenden, con la mayor autenticidad posible, narrar lo inenarrable, describir algo que sinceramente, no desea mirarse. De ahí que uno de los momentos más crudos de la historia, cuando el protagonista decide tatuarse un pentagrama en el pecho con cigarrillos, se enuncie en inglés por un narrador no reconocido: "He said the pain did not matter. Said Satan told her that the pain created the world [...]. I buried her cigarette in the boy's chest. Buried several cigarettes on the boy's chest. He did not cry. He asked to draw a star on the skin" (29).

En este punto, Bisama empleará un procedimiento ya analizado en los textos anteriores para garantizar que la transformación del modelo de mundo del protagonista sea efectivamente influyente en el entorno: la referencia a la absorción de la ideología del protagonista por parte de los jóvenes. "Después lo veía donde el Lucho, rodeado de pendejos que le hablaban" (31), contará una de sus novias; y luego lo confirma uno de sus seguidores, empleando, para su testimonio, un flujo de conciencia que resulta casi en un mantra: "huesos robamos huesos tibias fémures ropa dedos falanges dientes quijadas cráneos robamos huesos abrimos tumbas cavamos las manos llenas de barro" (31). La falta de puntuación y la ruptura sintáctica provocarán, eficazmente, que el efecto ominoso vaya en aumento en la novela. 
El protagonista, después, viaja de Castro a Valparaíso, de Valparaíso a Rancagua, y de Rancagua a Santiago, en donde ocurre el evento que funciona como eje para toda esta retrospectiva de la que la nouvelle da cuenta. Si en "Grindcore sudoku” la amenaza de la provincia para la capital estaba en estado latente, aquí realmente se concreta, cuando el personaje, convencido -a partir de esas voces que oye desde su niñez y que "nunca se equivocaban" (16), y de lo aprendido a través de la música y los libros alusivos al satanismo-, entra en la Catedral de Santiago, se sienta en las primeras filas y, con la cabeza cubierta por la capucha de un polerón, espera a que un sacerdote, de nombre Celerino, comience a celebrar la eucaristía, para acometer lo que, piensa, es su misión ${ }^{16}$ :

Se paró rápido, en el momento exacto en que el padre estaba consagrando la hostia. Lo agarró por la espalda. Tenía un cuchillo grande. Se lo enterró dos veces en el vientre. Le rasgó la ropa y le abrió el estómago. Los intestinos salieron afuera. El padre se dobló y trató de agarrarlos con la mano y cayó de rodillas. Él le tomó el pelo y le levantó la cabeza. El cuello quedó a la vista. Lo degolló de izquierda a derecha, dos veces. El padre se tomó el cuello con la otra mano, tratando de tapar la sangre. Después se desplomó. (39)

Tras el suceso, para algunos testigos el efecto de terror se intensifica, mientras que, para sus seguidores, la deformación ideológica se profundiza aún más: "Yo vi al diablo ahí atrás [...], un diablo de alas azules y cuernos, con el pecho abierto, un diablo que medía tres metros y que los acogía con sus alas" $(39,40)$, declara unos de los testigos. "Conchetumadre, del pecho le empezó a salir luz negra" (41), dice otro. "Cuando sea grande quiero ser como él” y "yo me tatué su cara en el brazo" (46), esgrimen a continuación unas voces anónimas y afectas.

Y es aquí, en estas páginas finales, donde lo que se ha construido ficcionalmente como una monstruosidad comienza a ser matizado, debilitado, bien por testimonios incrédulos, bien por aserciones que banalizan tanto a la figura del protagonista como a su misión. En el primer caso, en medio del homicidio algunos fieles trastocan su rol

${ }_{16}$ El suceso está inspirado, libremente, en el asesinato del padre Faustino Gazziero que se perpetró efectivamente en la Catedral de Santiago de Chile, el 24 de julio de 2004, por parte de Rodrigo Oria Gallardo: “Relatos de testigos sostienen que el atacante, quien vestía de negro y decía ser 'satán', se autoinfirió heridas, razón por la cual fue trasladado hasta la posta central, tras ser retenido por algunos feligreses" (El Mercurio online párr. 3). 
dentro de la Catedral y en lugar de ayudar al sacerdote o rezar, sacan sus teléfonos: "No me quedó otra que sacar la foto con el celular" (42), dice uno. Mientras fotografían o graban el suceso, otro recupera un recuerdo, descomprimido ya de la tensión que se ha venido manejando a lo largo de la novela, debido a su escepticismo: "Yo he visto esa mirada. Es la que tienen en el cine los actores que interpretan a los asesinos, a los caníbales, a los locos. No sé qué me pasó pero no le pude creer. Él no estaba loco. Se reía pero no estaba loco" (La cursiva es mía; 42). Ésta es una de las citas importantes para que aparezca el sabotaje metaficcional, y será otra vez el cine (el de los clichés, el de los patrones archiconocidos de las películas de terror) el que reluzca, esta vez para un propósito contrario al examinado en un principio: si para algunos personajes, incluyendo al protagonista, las películas de este corte habían deformado sus visiones del mundo y los habían incitado a determinados actos, para quien otorga este último testimonio el cine es la "lámpara" que le ha permitido desenmascarar un gesto aprendido por acto reflejo, y por ende, inauténtico.

El final de la nouvelle parece jugar, por tanto, a dos bandos. Si bien se multiplican las declaraciones de fascinación por el protagonista y su supuesto legado - "Nadie repara en que cuando él se borró, empezaron a quemar iglesias a lo largo de todo Chile" (48)-, el testimonio que pone punto final al relato de Bisama logra desmontar, desde el polo mismo de la generación de la narración y la historia (el testimonio colectivo), todo el devenir de su personaje y de los demás testimonios. Se trata de una opinión, y son apenas dos palabras agrupadas en un modismo típico de Chile para describir a aquellos que han ponderado en demasía su persona: "Entero póser" (54).

\section{6. Últimas palabras: por un terror distinto}

Como se ha visto, la estrategia saboteadora de Álvaro Bisama en sus relatos consiste en boicotear lo que pretende erigirse como ficción de género con un nivel metaficcional que tiende al escepticismo. De esta manera, los modelos de mundo en el que sus personajes se recrean son, de pronto, interferidos con el propósito de que esa transferencia performativa no alcance a convencer al lector real. Hablábamos, tomando prestado términos de la teoría de la poesía, que a nivel ficcional hay momentos de "euforia", pero a nivel metaficcional, donde el texto se vuelve crítico con sus propios enunciados y donde se produce el cortocircuito, el narrador 
presenta momentos evidentes de "disforia", de oclusión del relato que se puede estar articulando en pos de un género específico.

Esta característica, examinada en tres de sus textos breves, puede servir para establecer un estudio más amplio de la joven obra del autor, sobre todo si se estudian libros como Caja negra, Ruido y Música marciana. En un ensayo antes citado, el crítico Ignacio Álvarez afirmaba que en relatos como los de Bisama, denominados por él "epicúreos", "no solo lo percibido con los sentidos se acepta como verdadero; también se afirma la esencial verdad de los productos de la imaginación [...]" (21), explicando de manera adecuada que ante una realidad opaca, como la chilena contemporánea, los modelos de mundo venidos de "películas de directores chilenos de clase B, por ejemplo, poemas apócrifos de Gabriela Mistral [y] canciones de bandas de rock ficticias" (21) se imponían con cierta facilidad a los personajes. No obstante, como se ha analizado en este trabajo, la neutralización, el patetismo o el declarado castigo al que Bisama supedita a sus protagonistas parece llevarnos a un patrón narrativo donde el nombrado "epicureísmo" de Álvarez opera en un solo nivel del enunciado, el ficcional, para luego dar paso al "escepticismo". Es cierto que, en los textos de Bisama, todo se desordena, se trastoca, pero en algún punto regresa a su estado de equilibrio inicial. En esta lectura ideológica que hemos propuesto, las líneas de fuga, por tanto, se molarizan, lo que nos permitiría afirmar que estamos en presencia del más conservador de los escritores freaks de la narrativa chilena actual.

Bien señala Manuel Asensi que "puede haber textos téticos que muestren los límites de su modelo de mundo y pongan en crisis el silogismo, y textos atéticos que la oculten y creen un afepto entimemático, situación que requeriría un cambio de estrategia por parte de la crítica" (53). El rock, la literatura fantástica y de terror, el cine bizarro, los cómics y las lecturas alternativas a lo que, hasta la aparición de Bisama como crítico literario en Chile, resultaban textos canónicos para la crítica, orquestan ese afepto, efectivo y potente para cualquiera que se acerque a sus escritos. Sin embargo, el derrotero final de sus protagonistas y el limitado influjo de sus ideologías allí donde se desenvuelven, nos hacen pensar que el terror, concluyentemente, equivale a que lo alternativo y marginal ya ha sido axiomatizado y previsto por la máquina del capitalismo, y que ésta acabará codificándolo bajo sus normas. Las historias de los hijos del pintor 
surrealista chileno, en Música marciana; el relato del único músico y artista glam de Chile, en Caja negra; los testimonios que se multiplican en torno a Miguel Ángel Poblete, el “vidente” de Villa Alemana, en Ruido; o algunos cuentos, como "Patria automática" y "Muchacha nazi”, incluidos en Los muertos, sólo confirmarían lo anteriormente expuesto.

"A Álvaro Bisama le interesa complicar los inventarios de las librerías" señaló con total acierto Felipe Ojeda (2015) en un artículo. El asunto ha formado, desde siempre, parte de su proyecto, desde que causara polémica con su columna "El Come Libros" en El Mercurio, el periódico más conservador de Chile, propugnando la aparición de una literatura $B$ y una cultura alternativa. Al no encontrarla de manera exacta, fue él quien comenzó a producirla. Y tras una década en la palestra, sus sugestivos modelos de mundo parecen haberse impuesto de manera más efectiva en sus lectores reales que en sus personajes.

\section{Referencias bibliográficas}

Álvarez, Ignacio. "Sujeto y mundo material en la narrativa chilena del noventa y el dos mil: estoicos, escépticos y epicúreos". Revista Chilena De Literatura, no. 82, noviembre 2012, pp. 7-32.

Amaro, Lorena. "Parquecitos de la memoria: diez años de narrativa chilena (2004-2014)”. Revista Dossier, no. 26, Universidad Diego Portales, Facultad de Comunicación y Letras. Diciembre de 2014, http://www.revistadossier.cl/category/dossier-26/ page/2/.

Areco Morales, Macarena. “Cartografía de la novela chilena reciente”. Anales de Literatura Chilena, no. 15, año 12, junio 2001, pp. 179-186.

Aristóteles. Retórica. Gredos, Madrid, 1999.

Asensi Pérez, Manuel. Crítica y sabotaje. Barcelona, Anthropos, 2011.

- “Crítica límite/ El límite de la crítica”. Teoría literaria y deconstrucción. Madrid, Arco Libros, 9-78.

Benton, Glen Michael. "Mephistopheles”. Deicide. Roadrunner Discos, 1990.

Bisama, Álvaro y Tryno Maldonado. "Intercambio: Maldonado vs. Bisama”. Traviesa. Literatura contemporánea de cerca. 2013, http:// www.mastraviesa.com/Intercambio-Maldonado-vs-Bisama. 
Bisama, Álvaro, “Grindcore sudoku”. We rock. Ocho historias rápidas y pesadas. Santiago de Chile, Ediciones B, 2013.

"Póser". Machetazos. Todos mueren. Santiago de Chile, Ediciones B, 2013.

Los muertos. Santiago de Chile, Ediciones B, 2014.

Caminero, Juventino. Poesía española. Siglo XX. Capítulos esenciales. Kassel, Reichenberg, 1998.

Casas, Fabián. La supremacía Tolstoi y otros ensayos al tuntún. México, Seix Barral, 2016.

Cervantes, Miguel de. El ingenioso hidalgo don Quijote de la Mancha. Madrid, Real Academia Española y Asociación de Academias de la Lengua Española, 2004.

Curubeto, Diego . Cine bizarro. 100 años de películas de terror, sexo y violencia. Buenos Aires, Editorial Sudamericana, 1996.

Deleuze, Gilles y Félix Guattari. Mil mesetas. Capitalismo y esquizofrenia. Valencia, Pre-Textos, 2012.

El Mercurio en Internet. "Sacerdote muere apuñalado en Catedral de Santiago”. El Mercurio on line. 24 de julio de 2004, http://www. emol.com/noticias/nacional/2004/07/24/154005/sacerdotemuere-apunalado-en-catedral-de-santiago.html.

Fioretti, Roberto, Petrozza, Miland y Juergen Reil. “Son of Evil”. Kreator: Endless Pain. Noise Records, 1985.

Navarro, Desiderio. “Intertextualité. Treinta años después”. Intertextualité. Francia en el origen de un término y el desarrollo de un concepto. Selección, traducción del francés y prólogo de Desiderio Navarro. La Habana, Casa de las Américas-UNEAC-Embajada de Francia, 1997, pp. V-XIV.

Ojeda, Felipe, “Álvaro Bisama: Diccionario personal”. Revista Pánico, noviembre de 2015, http://www.paniko.cl/2015/11/ alvaro-bisama-diccionario-personal/.

Sánchez Carbó, José. La unidad y la diversidad. Teoría e historia de las colecciones de relatos integrados. Puebla, Universidad Iberoamericana, 2012.

Tolkien, J. R. R. El silmarillion. Barcelona, Minotauro, 2002. 